\title{
Projetos Sociais Esportivos: Vulnerabilização e Governo
}

\author{
Luiz Felipe Alcântara Hecktheuer \\ Méri Rosane Santos da Silva**
}

\begin{abstract}
Resumo: Este texto analisa os projetos sociais esportivos em funcionamento na cidade do Rio Grande-RS. Partindo de interrogações sobre o "social" destes projetos, são abordadas algumas de suas dimensões como: a responsabilização da sociedade e do indivíduo, as possibilidades de intervenção em educação não-formal, e o processo de segmentação de uma população de indivíduos nominados como vulneráveis vulnerabilização. Tais dimensões, neste estudo, constituem estes projetos sociais como estratégias e tecnologias de governamento dessas populações.
\end{abstract}

Palavras-chave: Projetos de Investimento Social . Esporte. Vulnerabilidade Social. Programas Governamentais

\section{Entre Paradoxos}

Este é o momento em que vivemos. Cada um com suas incertezas, algumas promessas não cumpridas e a quase impossibilidade de elaboração de outras. Não que nos seja proibido o empreendimento de elaborar promessas ou buscar certezas, mas as contingências, de certa maneira, apontam para seu impedimento. A grande promessa moderna de, pela escolarização plena da população, construir um estado de clareza pela racionalidade, de vidas livres e emancipadas e de espírito crítico, não se cumpriu mesmo que se tenha dado alargado crédito temporal ${ }^{1}$ para sua consecução.

\footnotetext{
*Programa de Pós-Graduação em Educação em Ciências.Universidade Federal do Rio Grande/ FURG. Curso de Licenciatura em Educação Física, FURG. Rio Grande, RS, Brasil. E-mail: felipao.rg@hotmail.com

${ }^{*}$ Curso de Licenciatura em Educação Física Programa de Pós-Graduação em Educação em Ciências. Universidade Federal do Rio Grande/FURG.. Rio Grande, RS, Brasil. E-mail: meri.rosane@hotmail.com

${ }^{1}$ Se considerarmos, com Michel Foucault, que se pode datar em torno do final do século XVIII e início do século XIX, o momento em que passamos da episteme clássica à moderna e que aí se dá a emergência - ou invenção - da escola moderna, já poderíamos, se isto fosse possível, estar presenciando o cumprimento pleno de seu projeto - o projeto moderno de sociedade. Sobre esta temática, no entanto, Veiga-Neto $(2000$, p. 205) considera que não se trata de dar crédito temporal à escola, mas de uma insatisfação com "aquilo que o lluminismo proclamou sobre ela,
} 
Somos efeito de um modelo de escolarização moderno e ao mesmo tempo elaboramos criticamente a sua falácia.

Este momento é paradoxal, não pela impossibilidade de optarmos por uma ou outra alternativa, mas por estarmos assistindo à falência de um projeto que, ao mesmo tempo em que neste vivemos, por este somos afetados e neste intervimos. Tal falência não está relacionada apenas ao projeto educacional moderno - onde a escola ocupa lugar central - mas, principalmente, ao lugar que a ciência e o modelo científico ocupam na modernidade.

Com suas promessas de acesso à "realidade tal como ela realmente é", "a" ciência moderna opera com certezas comprováveis - cientificamente - em um tempo em que estas certezas carecem de outros tipos de comprovação. É, neste tempo, que é o nosso, que emergem - ou são inventadas - outras possibilidades de educar e intervir pedagogicamente em lugares e tempos não escolares.

Neste texto, trata-se dos projetos sociais - especialmente os esportivos $^{2}$ - que se multiplicam ${ }^{3}$ e se constituem em intervenções contemporâneas. Tem-se assistido, desde o início dos anos 90 do

\footnotetext{
${ }^{2}$ Considerando que o material empírico em estudo são os projetos sociais esportivos, indico que, neste artigo, não discutiremos especificamente o tema esporte, mas que este serve como delimitador da análise aqui empreendida, já que, mesmo que este texto aponte para uma discussão que poderia atingir os projetos sociais em geral, não é de qualquer projeto que tratamos.

${ }^{3}$ Este texto baseia-se nos dados acumulados a partir de um mapeamento dos projetos sociais esportivos que tenham funcionado no período da pesquisa de doutoramento (2008-2011) ou que ainda se encontrem em funcionamento na cidade do Rio Grande-RS. Além destes, foram considerados os editais de financiamento de projetos, que, juntos, constituem o corpus empírico da pesquisa. Somadas estas condições, tomamos para análise os editais da Petrobrás (Programa Comunidades) e 27 projetos que são: "Segundo Tempo" (SMTEL/PMRG), "Bairros em movimento" (SMTEL/PMRG), "Verão Cassino" (SMTEL/PMRG), "Punhos da Esperança", "Semear", "Núcleo Jovem do Esporte", "Futsal", "Basquete de Rua", "Semente Olímpica - Investimento Social", "Siri Patola", "Mais Educação" (SMEC/PMRG), "Atleta do Futuro" (SESI), "Rio Grande rumo às olimpíadas" (SCRG), "Praticando Esporte e Estudando" (SCRG), "Campeões Olímpicos e campeões na vida" (SCRG), "Você pode ser um campeão olímpico de vôlei" (SCRG), "Educando pelo esporte" (SCRG), "Fertilizando Talentos" (YARA do BRASIL), "Formando Craques" (QUIP), "Craque cidadão", "Pró-Jovem" (SMEC/PMRG), "Retrato Falado", "Hip-Hop: Ser em Movimento" (ESCOLA ASSIS BRASIL), "Integração" (SMECPMRG), "Segundo Tempo" (IF-RS), "Elos de Amor", "MovimentAção" (SMTEL/PMRG).
} 
século passado, uma ampliação na oferta destes projetos ${ }^{4}$ com promessas parecidas com aquelas atribuídas à escolarização, sendo que aqui se observa um acento na produção da "cidadania" como um direito natural ${ }^{5}$. Em torno destes "projetos", os sociais, desenvolvese este texto. A motivação para isto decorre de certa desconfiança relacionada aos seus modos de funcionamento, principalmente, com o fato de dirigirem-se a crianças e adolescentes em situação de vulnerabilidade social ${ }^{6}$.

Podemos posicionar estes projetos como parte de um estado paradoxal ou como constituidor de diferentes outros paradoxos. Isto porque, de um lado, são propostos e produzidos a partir de "categorias" modernas como emancipação, evolução, transformação e libertação, o que os coloca no paradoxo da modernidade. De outro, estes mesmos projetos podem instaurar mecanismos de vulnerabilização dos indivíduos justamente quando se propõem a contribuir com a minimização de um estado de vulnerabilidade, o que estabelece um novo paradoxo.

Neste sentido, cabe, quase em forma de apêndice, uma descrição geral dos projetos que ajude a localizar e demonstrar em que nos apoiamos para chegar a pensar o que aqui está exposto. Analisar os projetos sociais esportivos e dedicar-se aos seus funcionamentos é consequência da proliferação dos mesmos, constituída como problema de pesquisa, ou seja, nunca estivemos preocupados em descrevê-los naquilo que "realmente" os caracteriza,

\footnotetext{
"Em "Cidadãos não vão ao paraiso", Zaluar (1994) analisa projetos desenvolvidos na década de 80 , criticando seu funcionamento a partir da redução da "carência ou desigualdade ao plano material" e dos "direitos de cidadania aos direitos sociais". Ainda que, em suas análises, a autora não demonstre desconfiança em relação ao papel que o esporte cumpre nestes projetos, esta obra é um marco na problematização dos projetos sociais esportivos e que, de certa maneira, identifica com certo ineditismo a proliferação destes projetos na sociedade brasileira.

${ }^{5}$ Reconhece-se aqui que o fato de haver necessidade de garantias na forma da lei, além de colocar em suspeita a naturalidade do que seja cidadão-cidadania, também não garante o acesso a sua plenitude.

${ }^{6} \mathrm{Em}$ sua maioria, os projetos sociais que compõem o corpus de análise assemelham-se neste sentido: são dirigidos aos indivíduos socialmente vulneráveis.
} 
mas procurar nestes o que os ativa simultaneamente, sem que para isso exista, ou seja necessária, uma orquestração (do Estado, por exemplo).

Para isto, tomamos por projeto social aqueles que se autonomeiam desta forma, que indiquem reivindicar tal status ou que apresentem "características" semelhantes aos anteriores, mas não utilizem nem reivindiquem tal denominação. Interessados que somos nas diferentes dimensões e manifestações esportivas, delimitamos, desta forma, nossas análises dos projetos sociais esportivos em funcionamento na cidade do Rio Grande -RS, ainda que, muito do que neste texto é abordado, possa ser estendido a projetos sociais que se utilizam de outros "veículos"7, que não o esporte, para atingir seus objetivos. Sobre as finalidades que projetos vinculados ao esporte como estes visam atingir, indicamos como exemplo, artigos que foram publicados em outras edições desta revista, analisando as relações que têm se estabelecido entre esporte e cidadania (MELO, 2004; 2005) e entre esporte e inclusão social (VIANNA; LOVISOLO, 2009).

Sendo assim, os vinte e sete (27) projetos mapeados podem ser distribuídos: pela iniciativa de sua proposição; pelos objetivos que visam atingir; pelo público-alvo a que se destinam; pelo local de funcionamento. Entretanto, seja os projetos que tenham como fim o próprio desenvolvimento do esporte, seja, os que tomam os esporte como meio para outros fins, é ao "social" que remetem com as vinculações que estabelecem com o "desenvolvimento" da cidadania, a "garantia" de direitos sociais, a inclusão e exclusão social, entre outros.

Sobre isto nos debruçamos a partir de agora. Quiséramos que se tratasse de ficções o que os caminhos de pesquisa nos demonstram, mas se nos achamos entre paradoxos, com certeza, não pretendemos resolvê-los, mas, sim, entender um pouco a maneira

7Destacamos que nos projetos "Atleta do Futuro" (SESI), "MovimentAção" (SMTEL/PMRG) e "Núcleo Jovem do Esporte", o esporte não é tomado como veículo ou meio para outros fins. Nestes, o objetivo é o próprio esporte, sua massificação e a garantia de acesso as suas práticas enquanto direito social. 
como são produzidos e como chegamos até os mesmos. Para isto, de início, questionamos sobre o social destes projetos, para, a partir daí, pensar os processos de responsabilização dos indivíduos e da sociedade, bem como o processo de segmentação e vulnerabilização ${ }^{8}$ de determinadas parcelas da população.

\section{INVENÇÃO E MORTE DO SOCIAL}

Partindo das análises que Foucault (2006, 2008a, 2008b) desenvolveu sobre uma arte de governo típica da modernidade razão política que denomina racionalidade de governo liberal - a sociedade não pode mais ser vista como possuindo uma natureza governável, mas, pelo contrário, como uma invenção de governo. $\mathrm{O}$ governo, por sua vez, passa a não ser visto como vinculado unicamente ao Estado, assim como a denominada sociedade civil não mais é ser reduzida ao que não é estatal em uma sociedade. Simplesmente porque as margens entre Estado e sociedade encontram-se borradas quando se trata de governo, por exemplo, quando a atuação de entidades não governamentais exerce, em alguns segmentos, o papel que seria do Estado ou quando é passada ao próprio indivíduo esta atribuição.

Neste sentido, o neoliberalismo ${ }^{9}$ deve ser tomado como algo diferente de uma sombra que se debruça sobre a sociedade, algo diferente de um ideário - razão de Estado - que vincula governo e Estado. Foucault (2006) fala de uma governamentalização do Estado

\footnotetext{
${ }^{8} \mathrm{O}$ que indicamos como sendo um processo de vulnerabilização está implicado, principalmente, com a forma como os projetos tomados para análise constituem uma população de vulneráveis e "alcançam" efetivamente esta população. Na nossa pesquisa estamos interessados na maneira como são convocados, selecionados e cadastrados os indivíduos identificados na população alvo desses projetos. Logo, o termo vulnerabilização, enquanto componente central da tese deste artigo está muito mais ligado ao processo de identificação e constituição de uma população, do que, de um processo de colocação destes indivíduos numa condição vulnerável. Além disso, na análise dos documentos dos projetos sociais encontra-se, ainda que em abundância, usos diferenciados para o termo vulnerável que consistem, para exemplificar, em: estar "sujeito á riscos" e possuir "necessidades e direitos" básicos não atendidos. Desta maneira, parece ser mais importante o uso do termo do que a definição do significado que the é atribuído nestes projetos.

${ }^{9}$ Rose (1996) refere-se ao neoliberalismo como "democracia liberal avançada".
}

Movimento, Porto Alegre, v. 17, n. 03, p. 115-132, jul/set de 2011. 
moderno, quando este assume a responsabilidade de governar gerindo não só as populações, mas cada indivíduo singularmente. Os projetos sociais, nesta perspectiva, não devem ser tomados como emanando unicamente do Estado (governo) e dirigidas às populações (governadas), mas como práticas que visam ao autogovernamento ${ }^{10}$ dos indivíduos e das populações.

Apoiado nas análises de Foucault, Burchell (1996) caracteriza a invenção e a montagem de uma arte liberal de governar, em que:

a sociedade civil era, para o liberalismo primitivo, uma espécie de conceito crítico, um instrumento de crítica. Esboçava o correlativo ou esquema para uma possível arte liberal de governo. No decorrer do século dezenove, e por todo o século atual, ela foi fundamentalmente refundida no que alguns chamam o social, ou apenas sociedade, por todas aquelas técnicas governamentais que associamos ao Estado do bem-estar. Hoje, sob a influência do que chamamos neoliberalismo, estamos testemunhando tentativas de mais uma vez transformá-la e habilitála para funcionar autonomamente, reformando seu modelo de ação característico (BURCHELL, 1996, p. 28$)^{11}$.

Nestes termos, o neoliberalismo afirma que o que chamamos "sociedade", então, é uma invenção de governo e, na verdade, não existe. E mais, o que chamamos de sociedade é um mecanismo governamental que "tem se tornado um obstáculo econômica e socialmente oneroso ao desempenho econômico do qual ele depende e leva inexoravelmente a um crescimento incontrolável do Estado. Há um sentido claro de que o neoliberalismo é anti-sociedade exatamente quando se opõe ao governo exorbitante" (BURCHELL, 1996, p. 27).

\footnotetext{
${ }^{10}$ Veiga-Neto (2005, p. 19) propõe que se utilize, em língua portuguesa, o vocábulo governamento, substituindo governo "nos casos em que estiver sendo tratada a questão da ação ou ato de governar." Esta sugestão está associada aos usos que têm sido feitos em língua portuguesa sobre as artes de governar, principalmente as análises foucaultianas, em que as práticas de governo não se restringem às práticas de Estado.

${ }^{11}$ Todos os fragmentos de texto extraídos de Burchell (1996) estão neste texto citados a partir de tradução livre do inglês.
}

Movimento, Porto Alegre, v. 17, n. 03, p. 115-132, jul/set de 2011. 
Quando políticas neoliberais afirmam que os projetos sociais, enquanto práticas deliberadas de governamento devem ocorrer sob responsabilidade da sociedade civil, é porque esta é tornada, ao mesmo tempo, objeto e objetivo do governo. Assim, além de uma autoresponsabilização da sociedade e dos indivíduos, passando por uma desoneração do Estado, produz-se o que Burchell (1996) denomina "autonomização da sociedade". Esta se dá "através da invenção e proliferação de novos modelos de ação quase econômicos, para a conduta independente de suas atividades". Produz-se, desta maneira, um empresariamento de todas as formas de conduta, ou melhor, "a organização de uma cultura empresarial [...] para a conduta de organizações até agora vistas como não econômicas, para a conduta de governo e para a conduta dos próprios indivíduos". O social passa a ser administrado, em termos de governo, como uma empresa e, no nível individual, constitui-se num correlato disto que podemos denominar "empresariamento de si mesmo".

É neste sentido que os investimentos de governo incidem sobre os indivíduos, mas de forma maciça sobre a população. Tudo que se pode saber sobre determinada população é produtivo em termos de governo sobre os outros. Não somente os dados de uma população interessam, mas, inclusive, a determinação de quem a compõe é alvo destes investimentos. Assim, são mapeadas populações cuja constituição tem relação estreita com o tipo de investimento que se pode propor sobre elas; como exemplo disso, pode-se utilizar a constituição de uma população de vulneráveis, simultaneamente objetivo e objeto dos projetos sociais esportivos.

A importância de se conhecer tudo que for possível sobre determinada população não é uma novidade. A cumplicidade demonstrada por Foucault entre a invenção das ciências estatísticas e as racionalidades modernas de governo aponta para isto. O que é novo é o tratamento do social a partir de indicadores empresariais como: cálculo de riscos, retorno de investimentos, indicadores de 
resultados, avaliação quantitativa, metas de produtividade, etc. Tais indicadores aparecem em editais ${ }^{12}$ de seleção para financiamento de projetos sociais, na elaboração e na avaliação da pertinência dos mesmos que são endereçados a determinadas comunidades que se constituem, entre outros fatores, a partir destes indicadores.

Se, de maneira rápida, se discorre sobre a invenção do social ou da sociedade como uma maneira diferente de situar (sitiar) este terreno, Rose (2007), por sua vez, nos fala da morte do social - o que não equivale às teses de morte ou fim da sociedade - ou de estratégias não sociais e de uma reconfiguração do território de governo. Para falar da morte do social, o autor identifica um deslizamento da noção de sociedade como algo a ser governado como tal, para a noção de comunidade em que os pertencimentos aparecem menos borrados e a atividade dos indivíduos parece estar mais próxima de suas necessidades. Neste deslizamento, o que aparece é justamente a atividade do indivíduo nas questões de governo. Isto não quer dizer que o termo comunidade seja novidade no pensamento político; a novidade fica por conta do fato deste terse tornado governamental. Trata-se, então, do "governo através da comunidade".

No hay duda de que una serie de otros cambios locales en el vocabulário em sitios diversos contribuyó al surgimiento de la comunidad como um antídoto alternativo válido o, incluso, como la cura de los males para los que lo social no tuvo respuesta -es más, para los males propios de lo social. (ROSE, 2007, p.119) [...] Sin embargo, la influencia de "lo social" sobre nuestra imaginación política se está debilitando. [...] Mientras nuestras autoridades políticas, profesionales, morales y culturales todavia hablan felizmente sobre la "sociedad", su significado y la preeminência ética de este término está bajo cuestionamento: "la

\footnotetext{
${ }^{12}$ Editais da PETROBRÁS e de seleção de projetos do Ministério do Esporte, como SEGUNDO TEMPO e PELC, são exemplares da utilização destes indicadores, relacionados não só para justificá-los, mas também como critérios de seleção das propostas a serem apresentadas.
} 
sociedad" es percibida como desintegrada en una variedad de comunidades éticas y culturales, con lealtades incompatibles y obligaciones incomensurables. (ROSE, 2007, p.146)

A(s) comunidade(s), em termos de governo, passa(m) a constituir, para as necessidades locais, o que a(s) população(ões) constitui(em) para a sociedade em geral. Como se trata de governar cada indivíduo, as lealdades a que este está vinculado, ou melhor, que o vinculam a outros tantos, constituem o que poderíamos denominar "populações menores", que precisam ser conhecidas, descritas, medidas, para fins de governo. Assim não somente o Estado, mas cada indivíduo e as comunidades a que mantém algum tipo de pertencimento são responsabilizados.

Devemos considerar, em uma discussão sobre comunidade, as advertências de Bauman (2003). Este autor nos ajuda a pensar o deslocamento da noção de "todo social" para comunidade, seja em termos identitários de pertencimento ou de configurações espaciais que buscam segurança. Não é difícil identificarmos este deslocamento, tanto no fato de indivíduos pertencerem, ao mesmo tempo, a diferentes comunidades (comunidades identitárias), como em comunidades geográfica e fisicamente fechadas em torno de si mesmas, de maneira a "garantir" um pouco de segurança (condomínios fechados, por exemplo). Aí, não é mais o bairro, a cidade, a nação que configuram um "todo social" que nos organiza e deve ser governado, mas, sim, comunidades que aproximam os indivíduos por seus interesses, de maneira menos dependente de categorias como nacionalidade, por exemplo.

\section{RESPONSABILIZAÇõES}

Entre a responsabilização da sociedade e do Estado pelo governo das populações e esta reivindicação contemporânea de que o sujeito seja ativo no seu próprio governo, identifica-se outra situação paradoxal em que se manifesta a desintegração do social, que Nikolas Rose (2007) diagnostica. 
De um lado, a sociedade civil é comumente caracterizada como "aquilo" que não faz parte do Estado. Esta pode ser considerada como espaço "de exercício da civilidade", "da cidadania", "de participação", propício à "emancipação social" e ao "desenvolvimento da autonomia". Entre os defensores do termo "sociedade civil" nesta perspectiva se apresentam várias interpretações:

desde aqueles que utilizam o termo como processo de privatização, implicando a expansão do mercado e a limitação do Estado, até liberais da corrente humanista, que atribuem como espaço da sociedade civil o processo de aprofundamento da participação comunitária em projetos públicos, aumentando a performance do governo e sua aceitação pública. Outros advogam como sinônimo de civilidade. Recentemente observa-se, no ocidente, o crescimento da interpretação da sociedade civil como aperfeiçoamento dos processos deliberativos democráticos, para criar mais espaço público. (GOHN, 2005, p.62)

Entretanto, é comum depararmo-nos com análises e interpretações que colocam em oposição Estado e sociedade civil, o que pode escamotear as relações de poder heterogêneas que se desenvolvem entre ambos e no interior de cada qual. Não menos comum é o anúncio e a utilização de termos como cidadania, emancipação, conscientização, participação, democratização, operando como representação unívoca de uma situação apoiada na realidade e referentes, eles mesmos, a interpretações "verdadeiras", acordadas e muito bem definidas.

De outro lado, o Estado investe na sociedade e no indivíduo no sentido de responsabilizá-los. Se Foucault (2006) localiza, a partir do século XVI, um processo de governamentalização do Estado ou estatização das formas de governo, em que a preocupação não é mais com o território, mas, sim, com as coisas a governar, pode-se anunciar, atualmente, um processo de desgovernamentalização do Estado, acompanhando o que Rose (2007) indica como sendo a morte do social. No entanto, isto não significa que o Estado abra mão de governar. O que Rose (2007) evoca com "desgovernamentalização 
do Estado" são arranjos nas estratégias e técnicas de governo que respondam principalmente às críticas dirigidas a uma racionalidade segundo a qual o Estado "governa demais".

Isto se explica porque, o governamento dos indivíduos, antes designado ao chefe de família e principalmente aos soberanos, passa a ser tarefa do Estado, que assume a responsabilidade de conduzir as condutas dos indivíduos para melhor gerir as populações. O Estado foi governamentalizado, desenvolvendo e aprimorando, a partir de então, tecnologias de governo não mais dos súditos, mas dos indivíduos que compõem as populações. Desta maneira, pode-se trabalhar com a hipótese de que os investimentos de diferentes ordens, feitos na área social, via sociedade civil, tem acarretado certa desgovernamentalização do Estado com transferência de responsabilidades para a própria sociedade civil. Pode-se dizer que, entre as ações que se organizam a partir desta matriz, localizam-se os projetos sociais propostos por variadas iniciativas e dirigidos a determinados indivíduos.

Neste sentido, o que se denomina responsabilidade social ${ }^{13}$ apresenta-se como possibilidade de proposição e desenvolvimento de ações sociais por parte de empresas privadas, muitas vezes, vinculadas à melhoria da sua imagem, pelo envolvimento destas em programas ou projetos sociais. Com a proposição de uma Lei de Responsabilidade Social, em tramitação no espaço legislativo nacional, anuncia-se a regulamentação de uma desresponsabilização do Estado em relação ao controle e à minimização de impactos à sociedade. Iniciativas como esta demonstram este "jogo" estratégico no qual estão envolvidos o Estado, o que tem sido denominado sociedade civil e os indivíduos ${ }^{14}$ que compõem as populações ou comunidades.

\footnotetext{
${ }^{13}$ Expressão atualmente em evidência que mantém relações principalmente com as corporações empresariais, daí existir, também, a expressão Responsabilidade Social Corporativa. Entre alguns dos projetos que compõem nosso corpus investigativo, os seguintes correspondem a este tipo de característica: "Fertilizando Talentos" (Yara do Brasil) e "Formando Craques" (QUIP).

${ }^{14}$ Autores como Elias (1994) e Castel (2010) argumentam que vivemos contemporaneamente em uma sociedade dos indivíduos, ou de indivíduos, suspeitando inclusive (o segundo), que não restaria mais do que apenas indivíduos.
} 
Em termos de governo, estas estratégias de responsabilização do social podem ser inscritas em dispositivos biopolíticos.

Tais dispositivos foram descritos e analisados por Foucault desde os desenvolvimentos sobre o biopoder ${ }^{15}$, a partir de Vigiar e Punir e, principalmente, das páginas finais da História da Sexualidade I, até os desdobramentos publicados em língua portuguesa ${ }^{16}$ no Nascimento da Biopolítica. É certo afirmar que muito aconteceu desde as análises empreendidas por Foucault, por isto, o que se vislumbra é a montagem de um quadro analítico pelo qual se possa fazer passar este acontecimento que é a proliferação da oferta de projetos sociais esportivos na contemporaneidade, levando em conta os desdobramentos dos dispositivos biopolíticos.

\section{SEGMENTAÇÃO DOS SERES VIVOS - PRODUÇÃO DE POPULAÇÕES DE VULNERÁVEIS - VULNERABILIZAÇÃO}

Nos projetos sociais analisados, pelo menos, na maioria deles crianças e adolescentes, ditos em situação de vulnerabilidade social ou risco social, são colocados como alvo de ações de governamento. Como se existisse um estado ou situação estável e muito bem definida, reconhecidos como referentes às expressões "vulnerável" e "em risco" ou "de risco". Nesta pesquisa, pretende-se inverter a noção que dirige ações programadas a indivíduos localizados em situação de vulnerabilidade, para a tese de que os discursos posicionam, constituem os sujeitos vulneráveis, ou seja, transformam indivíduos alvo de determinadas políticas e programas sociais em sujeitos posicionados num estado que se afasta da normalidade. Desta forma, tais políticas, programas e projetos funcionam como

\footnotetext{
${ }^{15}$ Trata-se de um poder que se exerce agora sobre a vida de uma população diferentemente, ainda que neste se apóie, do poder disciplinar que visa o corpo do indivíduo. Um poder que não mais "faz morrer", mas, sim, "faz viver".

${ }^{16} \mathrm{~A}$ publicação recente (2008), em língua portuguesa, dos Cursos do Collège de France, ministrados por Michel Foucault, nos anos 1977/1978 e 1978/1979, facilitou o acesso aos seus últimos desenvolvimentos sobre regulação das populações (FOUCAULT, 2008b) e dispositivos biopolíticos de governo (FOUCAULT, 2008a), possibilitando análises revigoradas sobre estas temáticas.
} 
tecnologias de governo, não necessariamente vinculadas ao Estado, que constituem uma população de vulneráveis para fins de governo, ou seja, "para se governar uma população é necessário isolá-la como um setor da realidade, identificar certas características e processos próprios dela, fazer com que seus traços se tornem observáveis, dizíveis, escrevíveis, explicá-los de acordo com certos esquemas explicativos. (ROSE, 1998, p. 36-37)

Antes de se constituírem como população ou comunidade, os vulneráveis são infames, estão por acaso dispersos. Só "aparecem por um instante à luz" (VEIGA-NETO, 1995, p. 19), quando capturados por programas ou projetos sociais. A este processo de captura e segmentação dos seres vivos em "populações menores" ou comunidades, denominamos vulnerabilização.

As discussões acerca de estados ou situações de vulnerabilidade socia $^{17}$ são datadas e localizadas no final do século XX. A partir delas, nesta pesquisa, trabalha-se com a tese de que muito mais do que se dirigir a um referente (individual ou populacional) em estado de vulnerabilidade, os projetos sociais vulnerabilizam cada indivíduo que é convocado, selecionado e cadastrado para o desenvolvimento de suas ações. Desta maneira, indivíduos passam a ser identificados e "contabilizados" como constituindo uma população ou comunidade (ROSE, 2007) de vulneráveis.

\section{EDUCAR E GOVERNAR}

Por fim, o empreendimento que visamos é pensar os projetos sociais como, ao mesmo tempo, técnica e estratégia, já que, educar e governar parecem ser o que movimenta a proliferação destes projetos. Por isso, tomá-los como "coisas" em termos de educação e de governo.

Neste sentido, a análise destas "coisas" diz respeito à educação porque desloca da escola, alguns mecanismos de correção e salvação

\footnotetext{
${ }^{17}$ Encontra-se em Silva (2008), discussão acerca do conceito vulnerabilidade social: de como se chegou a esta expressão e a que se refere em termos linguísticos.
} 
do humano que deveria existir em cada um de nós e porque se apropriou do pedagógico no que este tem de promessa e prescrição para alcançar resultados "seguros". O que se manifesta nas intervenções fora ${ }^{18}$ da escola carrega consigo muito do projeto moderno pedagógico vinculado e construído a partir desta. Logo, talvez seja mais apropriado quando nos referirmos ao educativo dos projetos sociais, tomá-los como "coisas" de educação não escolar, mesmo considerando novas polêmicas que tal posicionamento pode causar.

Os projetos sociais, além de ser coisa de educação, são de governo. Um governo em que se correlacionam e combinam técnicas e estratégias disciplinares e outras de ação de um(uns) sobre a ação do(s) outro(s) no governamento das condutas dos indivíduos e das populações. Governo ligado a uma razão política de Estado que não mais é controlada somente por este. Neste sentido, as técnicas, ou esta tecnologia de governo, foi desestatizada ou apropriada pela sociedade, onde o Estado ocupa seu espaço. Antes é de um governamento muito mais da regulação do que do controle coercitivo, está mais do lado da normalização biopolítica do que da normação ${ }^{19}$ disciplinar.

Isto fica demonstrado, para esta pesquisa, nas diferentes "origens" dos projetos sociais, produzida a partir de uma topografia que encontra e localiza os indivíduos no espaço ${ }^{20}$ e uma cartografia que mapeia os estados ou situações de vida ${ }^{21}$ destes indivíduos. Governamento, vulnerabilização e educação não escolar produzem, mapeiam, posicionam indivíduos como vulneráveis e desta maneira

\footnotetext{
${ }^{18}$ Assim, podemos afirmar que se trata de educação não formal, considerando autores como Gohn (2008), Park e Fernandes (2005), Park, Fernandes e Carnicel (2007), Simson, Park e Fernandes (2001) e Trilla, Ghanem e Arantes (2008), que trabalham com a divisão de educação formal, não formal e informal para designar o âmbito e a maneira onde e como funciona.

${ }_{19}$ Michel Foucault (2008b) estabelece esta distinção, associando normação mais ao exercício do poder disciplinar, e normalização, mais aos processos de subjetivação em relação às normas.

${ }^{20} \mathrm{Nas}$ periferias, nos arredores, nas margens urbanas do desenvolvimento.

${ }^{21} \mathrm{Em}$ risco, pobres, sem moradia, sem renda, sem educação etc.
} 
estratificam ou segmentam uma população de vulneráveis que "necessitam" ser retirados desta condição. Para governar vulnerabiliza-se. O esporte, a dança, a música e outras manifestações culturais têm sido apropriadas como meio para estes fins. 


\begin{abstract}
Social Sportive Projects: Vulnerabilization and Government

Abstract: This text analyzed the social sportive projects in action in the city of Rio Grande-RS. Starting from interrogations about the "social aspect" of these projects, we approach some of their dimensions like: the society and the individual responsibilization, the possibilities of intervention in non-formal education, and the segmentation process of a population of individuals named as vulnerable - "vulnerabilization". Such dimensions, in this study, constitute these social projects as strategies and technologies of government of these populations.
\end{abstract}

Keywords: Social Investment Projects . Sports. Social Vulnerability Government Programs

\title{
Proyectos Sociales Deportivos: Vulnerabiliza- ción y Gobierno
}

Resumen: Este texto analiza los proyectos sociales y deportivos en funcionamiento en la ciudad de Rio Grande-RS. Partiendo de interrogaciones sobre el "social" de estos proyectos, son abordadas algunas de sus dimensiones como: la responsabilidad de la sociedad y del individuo, las posibilidades de intervención en educación no formal, y el proceso de segmentación de una población de individuos nombrados como vulnerables - "vulnerablización". Tales dimensiones, en este estudio, constituyen estos proyectos sociales como estrategias y tecnologías de gobiernamento de estas poblaciones.

Palabras claves: Proyectos de Inversión Social. Deporte.Vulnerabilidad Social . Programas de Gobierno

\section{REFERÊNCIAS}

BAUMAN, Zygmunt. Comunidade: a busca por segurança no mundo atual. Rio de Janeiro: Zahar, 2003.

BURCHELL, Graham. Liberal government and techniques of the self. In: BARRY, Andrew; OSBORNE, Thomas; ROSE, Nikolas. Foucault and political reason: Liberalism, neo-liberalism and rationalities of government. Chicago: Chicago University Press, 1996.

FOUCAULT, Michel. Estratégia, poder-saber. 2.ed. Rio de Janeiro: Forense Universitária, Coleção Ditos e Escritos, , 2006. v.4 
FOUCAULT, Michel. Nascimento da biopolítica: curso dado no Collège de France (1978-1979). São Paulo: Martins Fontes, 2008a.

FOUCAULT, Michel. Segurança, território, população: curso dado no Collège de France (1977-1978). São Paulo: Martins Fontes, 2008b.

GOHN, Maria da Glória. Educação não-formal e cultura política. 4. ed. São Paulo: Cortez, 2008.

GOHN, Maria da Glória. O protagonismo da sociedade civil: movimentos sociais, ONGs e redes solidárias. São Paulo:Cortez, 2005.

MELO, M.. Lazer, Esporte e Cidadania: debatendo a nova moda do momento. Movimento (ESEF/UFRGS), Porto Alegre, v. 10, n. 2, p. 105-122, maio/ago. 2004. Disponível em: <http://seer.ufrgs.br/Movimento/article/view/2836/1449>. Acesso em: 17 Ago. 2011.

MELO, M.. A Vila Olímpica da Maré e as políticas públicas de esporte no Rio de Janeiro: um debate sobre a relação lazer, esporte e escola. Movimento (ESEF/ UFRGS), Porto Alegre, v. 11, n. 3, p. 89-106, set./dez. 2005. Disponível em: <http:/ /seer.ufrgs.br/Movimento/article/view/2884/1498>. Acesso em: 17 Jun. 2011.

PARK, Margareth; FERNANDES, Renata Sieiro (Org.). Educação não-formal: contextos, percursos e sujeitos. Campinas: UNICAMP/CMU; HOLAMBRA, São Paulo: Editora Setembro, 2005.

PARK, Margareth; FERNANDES, Renata Sieiro; CARNICEL, Amarildo (Org.). Palavras-chave em educação não-formal. Campinas: UNICAMP/CMU; HOLAMBRA, São Paulo: Editora Setembro, 2007.

ROSE, Nikolas. Governing "advanced liberal democracies". In: BARRY, A.; OSBORNE, T.; ROSE, Nikolas. Foucault and political reason: liberalism, neoliberalism and rationalities of government. Chicago, Chicago University, 1996. p. 3764.

ROSE, Nikolas. ¿La muerte de lo social?: Re-configuración del territorio de gobierno. Rev. argent. sociol., Buenos Aires, v. 5, n. 8, p. 113-152, jun. 2007 . Disponível em: $\quad$ http://www.scielo.org.ar/scielo.php?script=sci_arttext\&pid=S166932482007000100007\&lng=es\&nrm=iso >. Acesso em: 17 Jun. 2011.

ROSE, Nikolas. Governando a alma: a formação do eu privado. In: SILVA, Tomaz Tadeu da (Org.). Liberdades reguladas: a pedagogia construtivista e outras formas de governo do eu. Petrópolis: Vozes, 1998. p.30-45.

SILVA, Maurício Roberto da. Esporte, educação, estado e sociedade. Chapecó: Argos, 2007.

SILVA, Rose Méri Santos da. O discurso da vulnerabilidade social e os processos de constituição dos sujeitos "asematizáveis". 2008. $152 \mathrm{f}$. Dissertação (Mestrado) - Programa de Pós-Graduação em Educação Ambiental, FURG, Rio Grande, 2008. 


\section{ArtigosOriginais}

SILVA, Tomaz Tadeu da (Org.). Liberdades reguladas: a pedagogia construtivista e outras formas de governo do eu. Petrópolis: Vozes, 1998.

SIMSON, Olga Rodrigues de Moraes von; PARK, Margareth; FERNANDES, Renata Sieiro (Org.). Educação não-formal: cenários da criação. Campinas: Unicamp/ Centro de Memória, 2001.

TRILLA, Jaume; GHANEM, Elie; ARANTES, Valéria Amorim. Educação formal e não-formal: pontos e contrapontos. São Paulo: Summus, 2008.

VEIGA-NETO, Alfredo. Crítica pós-estruturalista e educação. Porto Alegre: Sulina, 1995.

VEIGA-NETO, Alfredo. Educação e governamentalidade neoliberal: novos dispositivos, novas subjetividades. In: CASTELO BRANCO, G. e PORTOCARRERO, V. Retratos de Foucault. Rio de Janeiro: Nau, 2000. p. 179-217.

VEIGA-NETO, Alfredo. Coisas de governo... In: RAGO, Margareth; ORLANDI, Luiz B. Lacerda; VEIGA-NAETO, Alfredo. Imagens de Foucault e Deleuze: ressonâncias nietzschianas. 2. ed. Rio de Janeiro: DP\&A, 2005. p. 13-34.

VIANNA, J., LOVISOLO, H.. Projetos de Inclusão Social através do esporte: notas sobre a avaliação. Movimento (ESEF/UFRGS), Porto Alegre, v. 15, n. 03, p. 145162, abr./jun. 2009. Disponível em: <http://seer.ufrgs.br/Movimento/article/view/5190/ 5583>. Acesso em: 17 Jun. 2011.

ZALUAR, Alba. Cidadãos não vão ao paraíso. São Paulo: Escuta; Campinas, SP: Editora da Universidade Estadual de Campinas, 1994.

Endereço para correspondência:

Universidade Federal do Rio Grande - FURG

Centro Esportivo, Campus Carreiros

Av. Itália km 8 - Bairro Carreiros

CEP: $96.201-900$

Rio Grande - Rio Grande do Sul - Brasil

Recebido em: 13.01.2011

Aprovado em: 11.08.2011

Movimento, Porto Alegre, v. 17, n. 03, p. 115-132, jul/set de 2011. 
